\title{
DIREITOS DOS ANIMAIS E A MANIFESTAÇÃO CULTURAL DO RODEIO NO BRASIL
}

Wesley Pablo Santos Caputo; Glaucia Aparecida Rosa Cintra

Universidade do Oeste Paulista - UNOESTE, curso de Direito, Presidente Prudente, SP. E-mail: wesleyunoeste@hotmail.com, glaucia@unoeste.br

\section{RESUMO}

A espécie humana durante todo seu período evolutivo parte da premissa do antropocentrismo, de que todos os recursos naturais são de uso exclusivo dos seres humanos. Diante disso, por séculos, os humanos ceifaram a vida e liberdade de diversos animais, buscando atender suas necessidades. Mesmo com a evolução da sociedade ainda existe manifestações culturais que se utilizam de animais, como os eventos de rodeios e suas modalidades. Assim, o presente trabalho tem por objetivo apresentar os conflitos de interesses entre a prática desses eventos e os direitos dos animais. Foi aplicado o método dedutivo legal, através de amplo levantamento bibliográfico, legal, jurisprudencial e de artigos eletrônicos. Conclui-se que os eventos de rodeios são práticas que resultam maus-tratos aos animais, não devendo a cultura prevalecer sobre os direitos destes, uma vez que a Constituição Federal veda a crueldade.

Palavras-chave: Conflito de Leis. Direito dos Animais. Rodeio. Senciência. Vaquejada.

\section{ANIMAL RIGHTS AND THE CULTURAL MANIFESTATION OF RODEO IN BRAZIL}

\begin{abstract}
The human species, through all the Evolution, comes from the anthropocentrism premise that: allnatural resources are exclusively for human beings use. As such, for centuries human beings have reaped the life and liberty from other animal species, searching for a way to sate their own needs. Even with society's evolution, there still is cultural manifestations that use animals, like rodeo and its modalities. Therefore, this work has the purpose to show the conflicts of interest between the practice of this events and the animals rights. It was applied the legal deductive method through extensive bibliographic, legal, jurisprudence and electronic articles research. The conclusion is that every rodeo manifestation result in animal's mistreatment, and so, the culture must not prevail above their rights, as the Federal Constitution banish cruelty.
\end{abstract}

Keywords: Conflicts of the law. Animal Rights. Rodeo. Sentience. Vaquejada. 


\section{INTRODUÇÃO}

Os seres humanos desde os primórdios, sempre se utilizaram dos recursos da natureza. Dentre tais manifestações, por séculos, os humanos ceifaram a vida e liberdade de diversos animais, a fim de atender suas necessidades.

Ocorre que atualmente a sociedade se encontra mais evoluída, sendo assim, menos dependente dos animais. Em razão desta evolução, a moral, ética e justiça dos seres humanos também se aprimorou, passando a deixar de lado o uso desnecessário de animais, tanto para práticas de trabalho como hábitos culturais.

Entretanto, em determinadas regiões brasileiras tais animais ainda continuam sendo utilizados nas arenas de rodeios e suas respectivas modalidades, a fim de atender à comunidade por tratar-se de uma cultura regional.

Diante disso, a justificativa se faz em função do interesse social, buscando estabelecer uma fundamentação legal com o escopo do fim dos eventos que utilizem animais, por ir contra os direitos destes seres.

Em razão disso, o presente trabalho tem por objetivo apresentar os conflitos de interesses perante a realização dos eventos de rodeios e suas modalidades. De um lado há o posicionamento dos defensores que apoiam a prática do rodeio, sob o fundamento de tratar-se de uma manifestação cultural, enquanto do outro, há argumentos seguindo o prisma do desrespeito aos direitos dos animais, em virtude do aspecto dos maus-tratos.

\section{METODOLOGIA}

Para atingir os objetivos propostos foi utilizado o método dedutivo legal, sendo realizado amplo levantamento bibliográfico, legal, jurisprudencial e de artigos eletrônicos, com intuito de contribuir para com a concretização dos direitos dos animais.

\section{CONFLITO DE LEI: RODEIO X DIREITO DOS ANIMAIS}

Sem sombras de dúvidas, a realização dos eventos de rodeio envolve alguns fatores que justificam seu fim, como o fator social cultural e o econômico. Desse feito, os adeptos desta prática encontram o devido respaldo legal para amparar a legalização dessa prática primitiva que apenas traz prazer aos seres humanos, colocando de lado o sofrimento dos animais que são acometidos por essa barbaridade.

Nas palavras de Fiorillo (2017, p. 273, grifo nosso):

Ainda que de duvidoso valor cultural, em face das modas de viola sertanejas, da religiosidade em certa medida existente quando dos encontros, bem como a presença do berrante e de comidas típicas, os rodeios sem dúvida alguma se destacam como importante atividade econômica vinculada ao lazer de brasileiros, principalmente nas regiões Centro-Oeste, Sul e Sudeste, levando às arenas do País muitas vezes público maior que o atraído pelo futebol nos estádios (segundo dados da Federação Nacional do Rodeio Completo, as 1.200 competições realizadas no Brasil no ano de 1997 reuniram 24 milhões de espectadores - sete vezes mais que os jogos do Campeonato Brasileiro de Futebol do mesmo ano).

Assim, de acordo com autor, por mais que a prática do rodeio tenha seu valor cultural questionável, o que predomina para a permissão desta prática se faz pelo lazer e o impacto econômico envolvido, principalmente nas regiões do interior, localidade com maior número de adeptos.

O rodeio, assim como a vaquejada, são práticas ocorridas principalmente no nordeste brasileiro. Tais eventos são considerados pela comunidade interessada como práticas culturais das devidas regiões, ou seja, faz parte do patrimônio cultural do povo, atendendo assim não apenas o fator social, mas também econômico. 
O elemento cultural é uma proteção estabelecida em nossa Carta Magna, prevista em seu artigo 215. "caput" e $\S 1$. (BRASIL, 1988), na qual indica que cabe ao Estado garantir o seu exercício.

Assim, os defensores das práticas de rodeio e vaquejada alegam que tais eventos devem ser autorizados a fim de garantir o interesse cultural dos povos, bem como protegidos, por serem considerados como patrimônio cultural brasileiro.

Ocorre que a visão antropocêntrica, pelo prisma de que todos os recursos naturais são inerentes de uso exclusivo do ser humano é uma das bases que mantêm as práticas de maustratos para com os animais de rodeios e afins.

Sobre isso, discorre Leite $(2015$, p. 385) que "Muitos autores defendem que o antropocentrismo foi, e continua sendo, um dos principais responsáveis pela degradação ambiental indiscriminada e pela submissão dos animais não humanos à crueldade.".

Um dos pontos de suma importância para a defesa dos direitos dos animais se faz pela compreensão da senciência animal.

A senciência, basicamente é a capacidade de reagir a estímulos, ou seja, a capacidade de sentir o que lhe afeta de forma positiva ou negativa, como por exemplo, alegria, dor, tristeza e outros.

A própria filosofia através de vários pensadores como Voltaire, Rousseau, Emmanuel Kant, Arthur Schopenhauer e outros, já entendiam que os animais possuíam a capacidade de sentirem emoções assim como nós, devendo assim, serem tratados com igualdade e dignidade.

Atualmente, a maior descoberta que ratificou o que já era nítido por séculos sobre o que tange a senciência dos animais, ocorreu em julho de 2012, onde um grupo de neurocientistas na conferência em Cambridge, confirmou que determinados seres vivos possuem consciência, conforme material da Veja (PIRES, 2016, grifo nosso):

Um grupo de neurocientistas - doutores de instituições de renome como Caltech, MIT e Instituto Max Planck - publicou um manifesto asseverando que o estudo da neurociência evoluiu de modo tal que não é mais possível excluir mamíferos, aves e até polvos do grupo de seres vivos que possuem consciência.

Diante disso, resta clarividente as provas consistentes no fato de que os animais, assim como nós seres humanos, são passíveis de sentirem emoções, qual seja, dor, tristeza, ansiedade, angústia, felicidade e afins, e justamente por isso não devem sofrerem maus-tratos ou qualquer tipo de exploração.

Entretanto, a ocorrência de maus-tratos é algo visível nesses eventos. Conceitua Sirvinskas (2017, p. 654, grifo nosso) a respeito de vaquejada que:

Essa modalidade de espetáculo é praticada por dois vaqueiros, montados em seus cavalos, os quais perseguem o boi desde a saída da sangra (boxe feito para a largada das reses) até a faixa de julgamento. Neste local os vaqueiros devem tombar o boi ao chão, arrastando-o brutalmente, até que mostre as quatro patas. Esses animais, geralmente, sofrem luxações e hemorragias internas, devido ao tombo.

Apenas pelas palavras de Sirvinskas já resta evidente as consequências fisiológicas geradas por estes eventos, em especial a vaquejada, resultando de forma nítida os maus-tratos dos animais.

Dando uma maior ênfase no conceito da crueldade, salienta Leite (2015, p. 403, grifo nosso):

[...] não há dúvidas de que, para o sistema legal brasileiro, crueldade é sinônimo de ato de abuso, maus-tratos, ferir ou mutilar o animal, sendo proibido expressamente pela Constituição Federal e criminalizado pela Lei n. 9.605/98, que, agora, busca não só a coerção de práticas cruéis, mas, para além disso, estabelece a preocupação em garantir o bem-estar dos animais não humanos. 
Em continuidade, é necessário no rodeio a utilização de alguns equipamentos como sinos, esporas, sedém, peiteira e a sela. Tais equipamentos são fundamentais, observado que sem eles seria praticamente impossível a realização do rodeio (SIRVINSKAS, 2017).

Um dos itens que causam tal efeito de coação é o sedém, equipamento que fica preso na virilha do animal, região muito sensível, fazendo a compressão desse local. Assim, os touros são estimulados a pularem, pois estão sofrendo com o desconforto do acessório comprimindo a região da virilha (FIORILLO, 2017).

A espora é outro item que deve ser observado. A espora é um apetrecho que é utilizado nas botas dos peões com o fim de garantir sua estabilidade em cima do animal, sendo este constantemente golpeado.

Não obstante os danos físicos por tais equipamentos, não se deve olvidar a possibilidade de queda dos animais. Com a queda, bem como um salto errado, pode levar a ocorrência de luxações, fraturas, entre outros danos físicos, sendo possível inclusive, levar o animal a óbito.

Não obstante os danos físicos, os animais estão constantemente sofrendo de forma psicológica. Nesse sentido, conforme notícia da revista Estadão (FREITAS et al., 2017, grifo nosso) explica sobre a vaqueja que:

[...] os bovinos são hoje enclausurados, açoitados e instigados para que corram quando aberto o portão, causando danos psicológicos comparados à tortura, bem como danos físicos sérios quando estão na arena, visto que em velocidade são agarrados pelo rabo e torcidos até cair com as quatro patas para cima, para serem dominado pelos vaqueiros.

Os danos psicológicos são uma realidade constante para estes animais, que são explorados contra sua vontade e são forçados a fazerem algo que não é da sua natureza, apenas gerando medo, dor e sofrimento.

Por fim, em paralelo aos danos mentais e psicológicos, tem o stress. Sobre isso, ratifica Fiorillo (2017, p. 273), que "Estudos de médicos veterinários estabelecem argumentos no sentido de que, além da dor física, o barulho, as luzes e as cordas usadas como apetrechos nos animais causam estresse.", ou seja, profissionais veterinários confirmam que a ocorrência de todo esse aglomerado causa estresse nos animais, consequentemente, maus-tratos.

Deve-se observar que o pomo do nosso direito, a Constituição Federal, não permite a crueldade contra os animais, conforme exposto no seu artigo 225. § 1.ㅇ, inciso VII (BRASIL, 1988). Cumpre ressaltar que a presente norma é de natureza difusa, ou seja, atinge a toda coletividade.

Consequentemente, o uso indevido da fauna para fins culturais na qual os animais são utilizados meramente para divertimento humano, não deve prosperar por ferir o instituto difuso assegurado pela Constituição Federal (FIORILLO, 2017).

Neste diapasão, a fundamentação da natureza difusa em relação aos animais é clara e objetiva. Os animais fazem parte do meio ambiente e as atitudes como maus-tratos e exploração destes não devem prevalecer pelo prisma ético-social e o interesse difuso.

\section{O QUE DEVE PREVALECER}

A questão cultural é um ponto que deve ser observado com cuidado. Alegar que os eventos de rodeios e vaquejadas são questões culturais, espetáculos tradicionais das regiões que presidem tal ato, é um argumento um tanto que questionável, visto que a tradição não justifica o sofrimento do animal. Para tal, devemos lembrar que o Brasil permitiu a escravidão entre a primeira metade do século XVI e o final do século XIX.

O conflito entre interesse cultural e a crueldade dos animais é algo tão tênue que a questão foi levada para o Supremo Tribunal Federal, conforme explica Sirvinskas (2017, p. 652, grifo nosso):

Essa discussão foi travada no Supremo Tribunal Federal, cuja decisão foi no sentido de proibir a prática de tal manifestação, prevalecendo o dispositivo mais favorável ao animal. 
Houve divergência no julgamento entre o ministro Maurício Corrêa e os ministros Francisco Rezek, Marco Aurélio, Néri da Silveira e CarlosVelloso. Em que pese essa divergência, a decisão foi pela proibição da prática da farra do boi. Nesse sentido:"Meio Ambiente. Crueldade a animais.'Farra do boi'.Alegação de que se trata de manifestação cultural. Inadmissibilidade. Aplicação do art. 225, § 10,VII, da CF.A obrigação de o Estado garantir a todos o pleno exercício de direitos culturais, incentivando a valorização e a difusão das manifestações, não prescinde da observância da norma do art. 225, § 1ㅇ,VII, da $\mathrm{CF}$, que veda a prática que acabe por submeter os animais a crueldade, como é o caso da conhecida 'farra do boi'".

Destarte, o próprio Supremo Tribunal Federal entende que o exercício cultural não deve prevalecer perante as práticas que submetam os animais a crueldade. Seguindo este prisma, Sirvinskas (2017, p. 655), aponta que "toda manifestação popular que submeta os animais a crueldade desnecessária deve ser coibida", demonstrando novamente desnecessidade da ocorrência de maus-tratos nos animas.

Em suma, é clarividente que a legislação não permite tais práticas culturais visto que apenas visa divertimento humano, sem qualquer preocupação com os animais. Assim, não deve ser considerado o rodeio, vaquejada e demais modalidades como tradição, uma vez que considerar a crueldade como cultura, nada mais é do que um pensamento retrógado, não evolutivo, já que nenhum tipo de divertimento deve ser exercido em função da exploração e sofrimento de outros seres, ou seja, dos animais.

\section{CONCLUSÃO}

Primeiramente, o presente trabalho, por meio da análise de julgados e principalmente pela descoberta da ciência, demonstrou a capacidade dos animais de possuírem consciência, consequentemente que são seres sencientes, passíveis de sentirem emoções como felicidade, tristeza, ansiedade, stress, dor, entre outros.

Em continuidade, estudou-se que a lei não permite a prática de crueldade aos animais, por estar prevista no artigo 225.ํ, § 1.ㅇ, inciso VII da Constituição Federal (BRASIL, 1988), sendo uma garantia de ordem constitucional e de natureza difusa. Destarte, não deve haver a exploração destes animais por serem tratados como bens difusos, logo não são passíveis de apropriação.

Quanto aos eventos de rodeios e suas respectivas modalidades, através da análise doutrinária, jurisprudencial e de profissional veterinário, foi apontado a ocorrência de maus-tratos aos animais nas arenas de rodeio. Os maus-tratos estão presentes tanto na questão física através da utilização de sedém, esporas, sinos e outros, como pelo aspecto psicológico, através do medo e trauma, não se olvidando do stress gerado em função do demasiado número de pessoas, barulho, claridade noturna.

Foi apresentado que em caso de conflito entre manifestação cultural e os direitos dos animais em função da crueldade, prevalece este último. O motivo dessa preponderância é que existe um viés doutrinário, jurisprudencial e até legal, em defesa da vida em prol da cultura, conforme exposto nos julgados do Supremo Tribunal Federal quanto a proibição das manifestações culturais da farra do boi, da rinha de galo, e recentemente, da inconstitucionalidade da lei do Ceará que legalizava a vaquejada, tudo sob o fundamento da ocorrência de crueldade e maus-tratos aos animais.

Em suma, através corpo legislativo, doutrinário e jurisprudencial, o presente trabalho trouxe a compreensão de que a dádiva da vida de um animal vem antes dos interesses culturais, pois embora estes também possuam amparo na égide constitucional, nada justifica a exploração e sofrimento à custa de outro ser vivo. 


\section{REFERÊNCIAS}

ANTUNES, Paulo de Bessa. Direito ambiental. 19. ed. São Paulo: Atlas, 2017. Disponível em: <https://integrada.minhabiblioteca.com.br/\#/books/9788597012316>. Acesso em: 30 abr. 2018.

BRASIL. Constituição da República Federativa do Brasil de 1988. Disponível em: <http://www.planalto.gov.br/ccivil_03/constituicao/constituicaocompilado.htm>. Acesso em: 30 maio 2018.

FIORILLO, Celso Antonio Pacheco. Curso de direito ambiental brasileiro. 17. ed. São Paulo: Saraiva, 2017. Disponível em: <https://integrada.minhabiblioteca.com.br/\#/books/9788547215255>. Acesso em: 30 abr. 2018.

FREITAS, Aline et al. Vaquejada e rodeio, patrimônio cultural. Disponível em: <http://opiniao.estadao.com.br/noticias/geral,vaquejada-e-rodeio-patrimoniocultural,70001636355>. Acesso em: 10 maio 2018.

LEITE, José Rubens Morato (coord). Manual de Direito Ambiental. São Paulo: Saraiva, 2015. Disponível em: <https://integrada.minhabiblioteca.com.br/\#/books/9788502622524>. Acesso em: 30 abr. 2018.

MORAES, Alexandre de. Direito constitucional. 34. ed. São Paulo: Atlas, 2018. Disponível em: <https://integrada.minhabiblioteca.com.br/\#/books/9788597016222>. Acesso em: 13 maio 2018.

OLIVEIRA, Adriana Maria Evaristo Martinez de. Normas e padrões para trabalhos acadêmicos e científicos da Unoeste. Presidente Prudente: Unoeste - Universidade do Oeste Paulista, 2015.

PIRES, Marco Túlio. Quase Humanos. Neurocinetístas publicam manifesto afirmando que mamíferos, aves e até polvo têm consciência e esquentam debates sobre direitos dos animais. Disponível em: <https://veja.abril.com.br/ciencia/quase-humanos/>. Acesso em: 10 maio 2018.

SIRVINSKAS, Luís Paulo. Manual de direito ambiental. 15. ed.

São Paulo: Saraiva, $2017 . \quad$ Disponível em: <https://integrada.minhabiblioteca.com.br/\#/books/9788547212513>. Acesso em: 30 abr. 2018. 